\title{
Salmonella Paratyphi B var Java infections associated with exposure to turtles in Bizkaia, Spain, September 2010 to October 2011
}

E Hernández (esther-ha@ej-gv.es) ${ }^{1}$, J L Rodriguez ${ }^{1}$, S Herrera-León ${ }^{2}$, I García ${ }^{3}$, V de Castro ${ }^{1}$, N Muniozguren ${ }^{1}$

1. Unidad de Epidemiología, Subdirección de Salud Pública de Bizkaia, Bilbao, Spain

2. Unidad de Enterobacterias, Centro Nacional de Microbiología, Instituto de Salud Carlos III, Majadahonda, Spain

3. Laboratorio Normativo de Salud Pública del Gobierno Vasco, Derio, Spain

Citation style for this article:

Hernández E, Rodriguez JL, Herrera-León S, García I, de Castro V, Muniozguren N. Salmonella Paratyphi B var Java infections associated with exposure to turtles in Bizkaia, Spain, September 2010 to October 2011. Euro Surveill. 2012;17(25):pii=20201. Available online: http://www.eurosurveillance.org/ViewArticle. aspx?Articleld=20201

Article submitted on 07 February 2012 / published on 21 June 2012

Between September 2010 and October 2011, the Unit of Epidemiology in the Department of Public Health in Bizkaia, Spain identified eight cases of Salmonella Paratyphi B var Java infection and three cases of infection with its possible monophasic variant 4,5,12:b:dT+. Six cases reported contact with turtles and $S$. Java was isolated from three of these turtles' habitats. The isolates from the patients and their respective turtles were indistinguishable by pulsed-field gel electrophoresis (PFGE). Although other reptiles can also carry Salmonella, turtles pose a special risk, as they are commonly kept as pets for children. This emphasizes the need to give recommendations regarding ownership and handling of aquatic turtles and other reptiles. As parents are often not aware of the risk of infection associated with the presence of turtles in the household, it would be appropriate to inform potential buyers at points of sale about the risk of infection and measures they can take to minimise this risk.

\section{Introduction}

Salmonella infections are predominantly acquired through the consumption of contaminated food, but contact with animals may also be an important source of infection [1]. Reptiles are frequent carriers of Salmonella in their intestinal tract [2], they usually show no signs of illness and shed the bacteria in their faeces, contaminating the water and any surface in contact with them [3-6].

Several Salmonella serotypes have been found in reptile-associated salmonellosis, including Salmonella Java, S. Poona, S. Pomona, S. Marina, S. Stanley, S. Litchfield, $S$. Newport and the most common serotypes, $S$. Typhimurium and $S$. Enteritidis [2-7].

Although other reptiles can also carry Salmonella, turtles pose a special risk, as they are commonly kept as pets for children.

S. Paratyphi B infections can cause enteric fever (paratyphoid fever) or gastroenteritis. In some cases, serious complications can occur (septicaemia, meningitis), especially in young children and immunocompromised patients [7].

S. Paratyphi B var Java shares the same somatic and flagellar antigens as $S$. Paratyphi B, but uses d-tartrate as a carbon source. This variant appears to be less virulent, causing infections characterised by watery diarrhoea, abdominal pain and fever, although infection can also be invasive. In sporadic cases and outbreaks, infection with $S$. Java has been associated with consumption of contaminated food, including salads, goat's milk cheese and poultry and with contact with reptiles and tropical fish aquariums [8-11].

The Epidemiology Unit of the Department of Public Health in Bizkaia (a territory of the Basque Country, in the north of Spain, with a population of nearly 2,150,000 inhabitants) identified, between September 2010 and October 2011, 14 cases of S. Paratyphi B infection (incidence rate: $0.65 / 100,000$ inhabitants). In Spain, the most common Salmonella serotypes are Enteritidis and Typhimurium. S. Paratyphi B biovar Java represented $2.1 \%, 1.4 \%$ and $1.7 \%$ of the Salmonella strains isolated from humans and serotyped at the National Reference Laboratory for Salmonella in 2009, 2010 and 2011 respectively. As S. Java is an unusual serotype, an investigation was initiated to identify the risk factors.

\section{Methods}

A case was defined as a patient, resident in Bizkaia, who had an isolate of $S$. Paratyphi B var Java between September 2010 and October 2011.

Adult cases and the parents of the affected children were contacted by telephone and questioned using a standard questionnaire about potential risk factors, such as other cases of gastroenteritis in their environment, travel, consumption of suspected food items and animal exposure. Where contact with turtles was 


\section{FIGURE 1}

Cases of Salmonella Java and its possible monophasic variant by age group and exposure to turtles, Spain,

September 2010-October $2011(\mathrm{n}=11)$

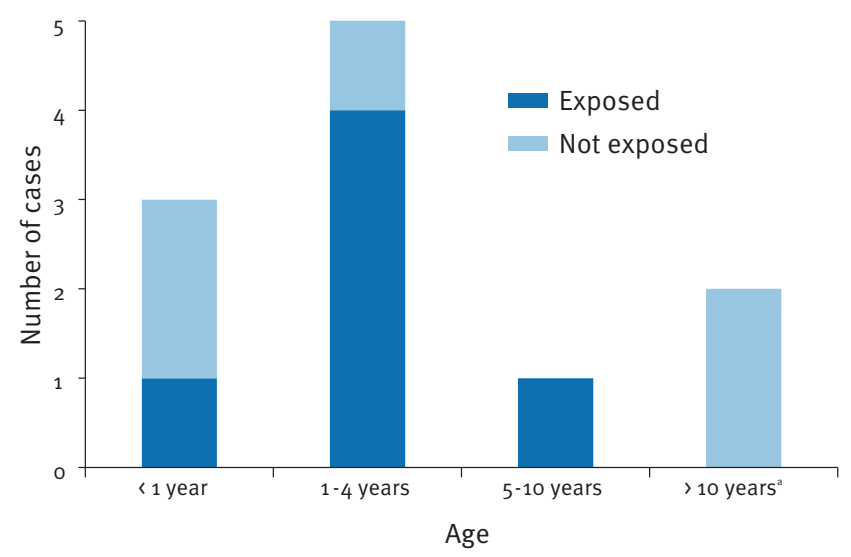

a Two adults in their mid-20s and early 6os.

reported, a water sample was collected from the turtle's aquarium or terrarium for Salmonella testing. Another water sample was taken from the turtle tank at the shop where one of the turtles was bought, for laboratory analysis. The detection of Salmonella in the water samples was performed using enzyme-linked fluorescence assay (ELFA) method (bioMérieux's VIDAS) and by culture (ISO 19250 Water quality-detection of Salmonella spp.).

Isolates from patients and environmental samples which were positive for $S$. Paratyphi B were submitted for confirmation to the reference laboratory, National
Centre for Microbiology, Carlos III Institute of Health, Madrid, Spain. The strains were typed using phenotypic (lead acetate method) and molecular methods to detect the tartrate reaction [12]. Susceptibility to antimicrobials was tested by the disc diffusion method according to Clinical and Laboratory Standards Institute (CLSI) guidelines [13]. The panel included the following antimicrobials: ampicillin, cefalotin, cefotaxime, amoxicillin/clavulanic acid, tetracycline, streptomycin, kanamycin, gentamicin, nalidixic acid, ciprofloxacin, chloramphenicol, trimethoprim/sulfamethoxazole and a sulphonamide compound (sulfadiazine, sulfathiazole and sulfamerazine sodium). The Xbal-PFGE patterns of strains were compared according to the PulseNet protocol [14].

Three of the 14 cases, identified as S. Paratyphi B, were excluded from the investigation because they were not S. Java or its variant.

\section{Results}

Out of the 14 strains of S. Paratyhi B studied, eight were identified as S Paratyphi B variant Java (S. Java), three as possible monophasic variants of $S$. Java (S. 4,5,12:b:-), and three as S. Paratyphi B sensu stricto. The last three, which came from a family outbreak involving three siblings, produced different clinical manifestations, and were excluded from this description.

The 11 patients from whom $S$. Java or its possible monophasic variant was isolated were not related to each other, and developed a mild disease, with symptoms of gastroenteritis.

Except for two adults in their mid-20s and early 60s, all cases were children aged between three months and

\section{TABLE}

Description of cases and laboratory results, Salmonella Paratyphi B var Java infections, Spain,

September 2010-October $2011(\mathrm{n}=11)$

\begin{tabular}{|c|c|c|c|c|c|c|}
\hline \multirow{2}{*}{ Case } & \multirow{2}{*}{ Age group (years) } & \multirow{2}{*}{ Turtle exposure } & \multicolumn{2}{|c|}{ Pacient } & \multicolumn{2}{|c|}{ Turtle's water } \\
\hline & & & Serotype & PFGE & Result (Serotype) & PFGE \\
\hline 1 & $5-10$ & yes & Salmonella Java & Type 1 & negative ${ }^{a}$ & NA \\
\hline 2 & $1-4$ & yes & S. Java & Type 1 & negative $^{\mathrm{a}}$ & NA \\
\hline 3 & $210^{b}$ & no & S. Java & Type 1 & NA & NA \\
\hline 4 & $1-4$ & yes & S. Java & Type 1 & S. Java & Type 1 \\
\hline 5 & $\ll 1$ & no & 4,5,12:b:- & Type 2 & NA & NA \\
\hline 6 & $1-4$ & no & S. Java & Type 2 & NA & NA \\
\hline 7 & $\langle 1$ & yes & S. Java & Type 2 & S. Java & Type 2 \\
\hline 8 & $5-10$ & yes & S. Java & Type 2 & S. Java & Type 2 \\
\hline 9 & $\ll 1$ & no & 4,5,12:b:- & Type 3 & NA & NA \\
\hline 10 & $1-4$ & yes & 4,5,12:b:- & Type 3 & negative $^{\mathrm{a}}$ & NA \\
\hline 11 & $>10^{b}$ & no & 4,5,12:b:- & Type 3 & NA & NA \\
\hline
\end{tabular}

NA: not applicable; PFGE: pulsed-field gel electrophoresis.

a These samples were taken with a delay of five to 13 months after the infection.

b Adults in their mid-20s and early 6os. 
Dice (Opt:1.00\%) (Tol 1.5\%-1.5\%) (H>0.0\% S>0.0\%) [0.0\%- 100.0\%] PFGE -Xbal

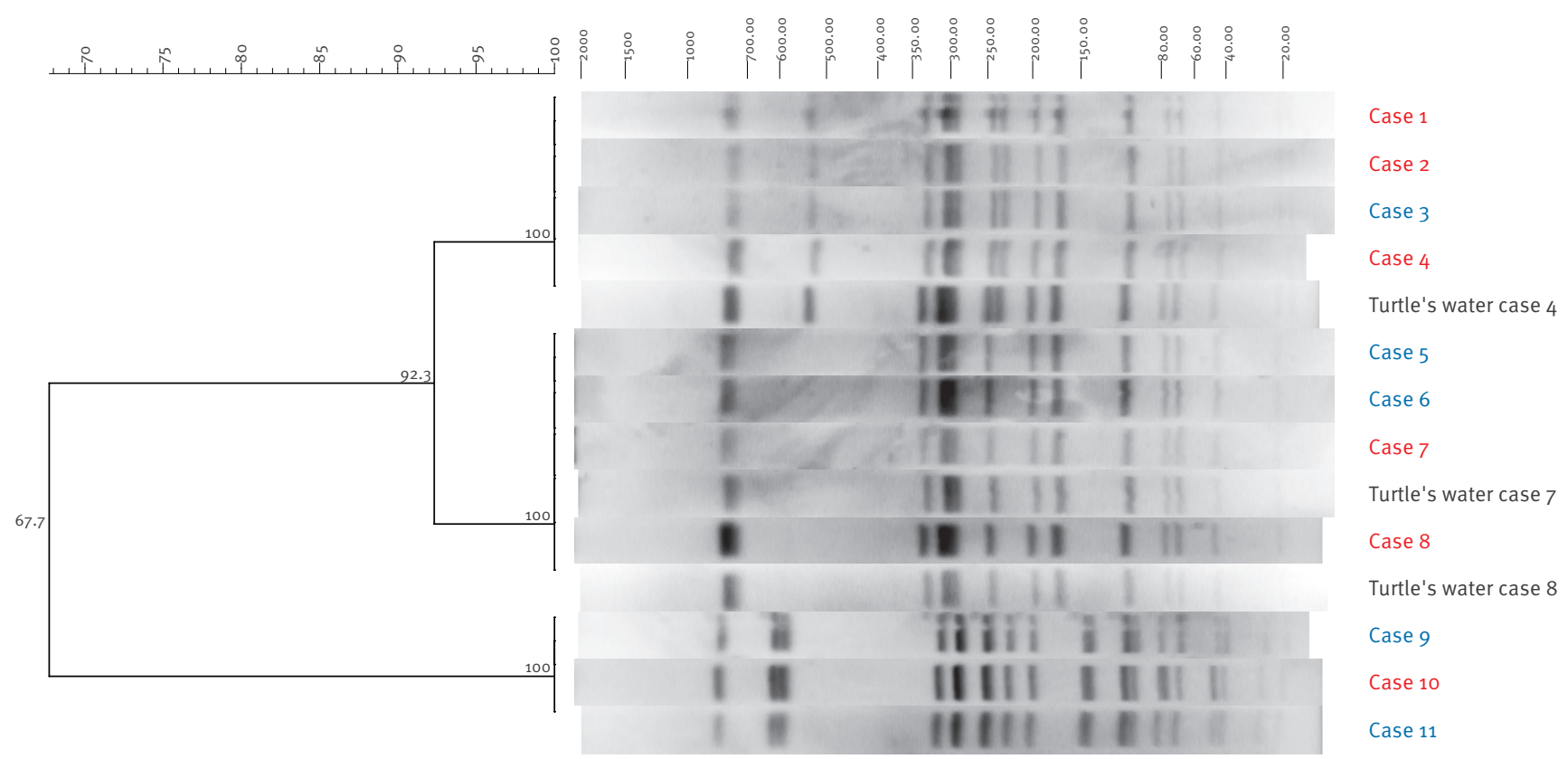

PFGE: pulsed-field gel electrophoresis.

Cases in red: exposed to turtles.

Cases in blue: not exposed turtles.

10 years. Six of the cases among children were male and three were female).

During the interviews, the only common factor found to constitute a risk according to the literature was having been in contact with aquatic turtles during the days before illness onset in six of the nine children, either at home (four cases), or at a relative's house (one case) or at school (one case).

The laboratory results show three different PFGE profiles, which we call type 1, 2 and 3 (Table, Figure 2). All strains were fully susceptible to all antimicrobials tested.

Three of the six samples of turtle's water yielded Salmonella Java, with the same PFGE patterns as the bacteria isolated from the children who had contact with them. Two of them were type 2, and the other was type 1 . The three negative results came from samples collected more than five months after the infection.

The turtles were purchased at different shops and the supplier or suppliers could not be identified.
The PFGE patterns of isolates of patients with and without turtle exposure were indistinguishable, although the source of infection could not be found. All PFGE profiles were compared with those deposited at the PulseNet network and no match was found.

The water sample taken from the shop where the turtle of case 8 had been bought yielded Salmonella serogroup $\mathrm{C}$. This turtle belonged to the subspecies Trachemys scripta scripta. The species of the other turtles are not known.

\section{Discussion}

Although we lacked a control group, the epidemiological and laboratory findings from our investigation indicate that turtles were the most likely source of infection with $S$. Paratyphi B var Java or its possible monophasic variant in this cluster of cases. Although any Salmonella serotype may be carried and transmitted by turtles, $S$. Java has been particularly associated with these reptiles [4].

For the first time, a possible monophasic variant of $S$. Java associated with reptile contact is described. 
This is the second time we find an association between contact with turtles and Salmonella infection. In 2008, following an increase in $S$. Typhimurium infections in our region, a case-control study was performed, which estimated the odds of infection to be 1.62 times higher if the case had been exposed to turtles ( $95 \%$ confidence interval ( $\mathrm{Cl})$ : 0.68-3.89). In this study, 67/145 (46.2\%) of cases were children aged between one and four years and $24 / 138(17.4 \%)$ of cases reported contact with turtles. The association between reptile exposure and Salmonella infection has been described in several countries [2-7,15-18].

Most cases of turtle-associated salmonellosis occur in young children, who are in the most susceptible age spectrum, probably because they usually have a closer contact with these pets, and play with the aquarium water, which is a good medium for the growth of Salmonella. Moreover, their hygiene practices tend to be worse than those of adults $[2,15]$. In addition, parents are often not aware of the risk of infection associated with the presence of turtles in the household.

Not all the cases in this cluster reported exposure to turtles. However, direct contact is not necessary for infection; environmental contamination and symptomatic or asymptomatic patients represent possible sources of infection that may have gone unnoticed. As Salmonella bacteria survive in the environment for a long time $[2,5]$, indirect transmission can play an important role.

Three of the six samples of turtle's water tested negative. However, Salmonella shedding can be intermittent and increase in response to stress like crowding, living in an environment with inadequate temperature, humidity or cleanliness, transportation, a change of habitat or excessive handling. A negative result doesn't rule out the possibility of intermittent water contamination $[2,5]$. For this same reason, a mixed infection in the water of the shop where Salmonella serogroup C was found is possible.

In the United States of America (USA), the association between contact with small turtles and Salmonella infection lead, in 1975, to a ban on the sale and distribution of turtles under $10.2 \mathrm{~cm}$ in carapace length, except for scientific or educational purposes. As a consequence, an important reduction in the number of Salmonella infections was observed in the following years, especially among children [2-5]. Since then, many sporadic turtle-associated salmonellosis cases have been detected.

In recent years, there has been an increase in the number of reptiles kept as pets, as well as in the number of infections linked to contact with reptiles, including more common serotypes, such as Typhimurium [2-4]. Currently, an estimated $6 \%$ of Salmonella infections in the USA are caused by direct or indirect contact with reptiles [4]. In February 2012, the Centers for Disease
Control and Prevention (CDC) reported 132 cases of S. Paratyphi B var. L (+) tartrate + infection between 5 August 2010 and 26 September 2011. The median age of the patients in this outbreak was six years and of the 56 patients interviewed, 36 reported turtle exposure [19].

In Europe, Salmonella infection cases attributed to direct or indirect contact with reptiles have also been described, although the number is likely to be underestimated, as in many cases the source of infection is unknown [17]. In Sweden for instance, between 1990 and 2000, 339 reptile-associated Salmonella infections were reported, accounting for approximately $5 \%$ of all reported cases [5]. In this country, from 1970 to 1994, a certificate was required for the import of reptiles, stating that the animals were free of Salmonella, and the commercial distribution of turtles with a carapace length less than $10.2 \mathrm{~cm}$ was banned. When import regulations ceased, an increase in the number of cases was observed between 1996 and 1997. After a public education campaign launched in 1997, the number of cases decreased again [20].

Attempts to eliminate Salmonella from turtles by antibiotic treatment have not been successful, as the animals readily become reinfected from the environment, food or other turtles and can result in the development of antibiotic resistance. As Salmonella shedding may be intermittent and related to stress, it is difficult to determine whether turtles are free of bacteria [2]. For this reason, the way to prevent transmission is to avoid contact of susceptible persons with turtles and to follow strict hygiene practices to minimise the risk of infection.

In the US, apart from the restrictions on the sale of small turtles, there are recommendations published by CDC for preventing reptile-associated salmonellosis, which include washing hands after handling reptiles and keeping reptiles away from food and food preparation areas [21].

\section{Conclusions and recommendations}

In conclusion, there is a risk of Salmonella infection linked to contact with turtles, which emphasises the need to give recommendations regarding ownership and handling of aquatic turtles and other reptiles kept as pets by young children. These recommendations can also apply to immunocompromised persons. It would also be appropriate to give information to potential buyers at points of sale about the risk of Salmonella infection and measures that can be taken to minimise this risk.

A report of this outbreak with the following recommendations was sent to the public health authorities and the Department of Agriculture in Bizkaia so that preventive measures can be taken. 
Recommendations given for preventing Salmonella infection from turtles included:

- washing hands with water and soap immediately after handling turtles (or other reptiles);

- cleaning and disinfecting surfaces that have been in contact with the animal;

- not using the kitchen to wash the aquarium/terrarium (if the bathroom is used, this should be disinfected after use);

- avoiding contact of the turtle with food (turtles should not live in the kitchen or roam freely in the house);

- avoiding contact of especially susceptible people (children under five years, pregnant women, patients with cancer or undergoing chemotherapy treatment, transplanted patients, persons with diabetes, hepatic conditions or other immunocompromised persons) with turtles and any object that has been in contact with them.

\section{Acknowledgments}

We thank Ildefonso Perales (Laboratorio de Microbiología, Hospital de Cruces), José Luis Díaz de Tuesta (Laboratorio de Microbiología, Hospital de Basurto), Patricia Sáez de la Fuente (Laboratorio de Microbiología, Hospital de Galdakao), Iñaki Arrázola and José Miguel Escribano (Departamento de Agricultura, Diputación Foral de Bizkaia).

\section{References}

1. Musto J, Kirk M, Lightfoot D, Combs BG, Mwanri L. Multi-drug resistant Salmonella Java infections acquired from tropical fish aquariums, Australia, 2003-04. Commun Dis Intell. 2006;30(2):222-7.

2. Centers for Disease Control and Prevention (CDC). Multistate outbreak of human Salmonella infections associated with exposure to turtles: United States, 2007-2008. MMWR Morb Mortal Wkly Rep. 2008;57(3):69-72.

3. Mermin J, Hutwagner L, Vugia D, Shallow S, Daily P, Bender J, et al. Reptiles, amphibians, and human Salmonella infection: a population-based, case-control study. Clin Infect Dis. 2004;38 Suppl 3: S253-61.

4. Harris JR, Neil KP, Behravesh CB, Sotir MJ, Angulo, FJ. Recent multistate outbreaks of human Salmonella infections acquired from turtles: a continuing public health challenge. Clin Infect Dis. 2010;50(4):554-9.

5. Hoelzer K, Moreno Switt Al, Wiedmann M. Hoelzer et al. Animal contact as a source of human non-typhoidal salmonellosis Vet Res. 2011;42(1):34.

6. Wells EV, Boulton M, Hall W, Bidol SA. Reptile-associated salmonellosis in preschool-aged children in Michigan, January 2001-June 2003. Clin Infect Dis. 2004;39(5):687-1.

7. Nagano N, Oana S, Nagano Y, Arakawa Y. A severe Salmonella enterica serotype Paratyphi infection in a child related to a pet turtle, Trachemys scripta elegans. Jpn J Infect Dis. 2006;59(2):132-4.

8. Gobin M, Launders N, Lane C, Kafatos G, Adak B. National outbreak of Salmonella Java phage type $3 \mathrm{~b}$ variant 9 infection using parallel case-control and case-case study designs, United Kingdom, July to October 2010. Euro Surveill. 2011;16(47):pii=20023. Available from: http://www. eurosurveillance.org/ViewArticle.aspx?Articleld=20023

9. Denny J, Threlfall J, Takkinen J, Löfdahl S, Westrell T, Varela C, et al. Multinational Salmonella Paratyphi B variant Java (Salmonella lava) outbreak, August - December 2007. Euro Surveill. 2007;12(51):pii=3332. Available from: http://www. eurosurveillance.org/ViewArticle.aspx?Articleld=3332

10. Chart $\mathrm{H}$. The pathogenicity of strains of Salmonella Paratyphi b and Salmonella Java. J Appl Microbiol 2003;94(2):340-8.
11. Levings RS, Lightfoot D, Hall RM, Djordjevic SP. Aquariums as reservoirs for multidrug-resistant Salmonella Paratyphi B. Emerg Infect Dis. 2006;12(3):507-10.

12. Malorny B, Bunge C, Helmuth R. Discrimination of d-tartratefermenting and -nonfermenting Salmonella enterica subsp. enterica isolates by genotypic and phenotypic methods. J Clin Microbiol. 2003;41(9):4292-7.

13. Clinical and Laboratory Standards Institute (CLSI). Performance standards for antimicrobial susceptibility testing; twenty-first informational supplement. CLSI document M100-S21. Wayne, PA: CLSI; 2011.

14. Centers for Disease Control and Prevention (CDC). PulseNet Protocols. Salmonella. Atlanta: CDC. [Accessed 20 Jun 2012]. Available from: http://www.cdc.gov/pulsenet/protocols.htm

15. Stam F, Römkens TE, Hekker TA, Smulders YM. Turtleassociated human salmonellosis. Clin Infect Dis. 2003;37(11):e167-9.

16. Centers for Disease Control and Prevention (CDC). Turtleassociated salmonellosis in humans - United States, 20062007. MMWR Morb Mortal Wkly Rep. 2007;56(2):649-52.

17. Editorial team, Bertrand S, Rimhanen-Finne R, Weill FX, Rabsch W, Thornton L, et al. Salmonella infections associated with reptiles: the current situation in Europe. Euro Surveill. 2008;13(24): pii=18902. Available from: http://www. eurosurveillance.org/ViewArticle.aspx?Articleld=18902

18. Aiken AM, Lane C, Adak GK. Risk of Salmonella infection with exposure to reptiles in England, 2004-2007. Euro Surveill. 2010;15(22):pii=19581. Available from: http://www. eurosurveillance.org/ViewArticle.aspx?Articleld=19581

19. Centers for Disease Control and Prevention (CDC). Notes from the field: outbreak of salmonellosis associated with pet turtle exposures-United States, 2011. MMWR Morb Mortal Wkly Rep. 2012;61(4):79

20. De Jong B, Andersson Y, Ekdahl K. Effect of regulation and education on reptile-associated salmonellosis. Emerg Infect Dis. 2005;11(3):398-403.

21. Centers for Disease Control and Prevention (CDC). Healthy Pets Healthy People (HPHP). Is a turtle the right pet for your family? Atlanta: CDC. [Accessed 20 Jun 2012]. Available from: http:// www.cdc.gov/healthypets/spotlight_an_turtles.htm 